DOI https://doi.org/10.18551/rjoas.2017-12.27

\title{
MARKET ECONOMICS PRINCIPLES OF EDUCATION
}

Ivanova O., Candidate of Economic Sciences

Kharkiv Humanitarian University «People's Ukrainian Academy», Kharkiv, Ukraine

Astakhova E. *, Candidate of Economic Sciences

Vladivostok State University of Economics and Service, Vladivostok, Russia

\section{*E-mail: evastahova1@yandex.ru}

\begin{abstract}
Education is an important component of social and economic development. Company represented by the public, corporate, private sector households across the demand for professionals in the goal-setting exercise education. This article analyzes the principles of the education in the market economy. The types of market structures at the education market in the conditions of high schools competition are considered.
\end{abstract}

\section{KEY WORDS}

Education, economics, university's competitiveness, human capital.

Basic principle of the human capital theory that stresses the role of education as a productivity enhancing investment (Becker 1964) is widely accepted in this discussion. Education policy is directed to meet the skill needs of the modern workplace and to improve the performance of the individuals in the labor market. In fact, education is seen almost as a universal cure to some of the most severe economic problems such as unemployment and poverty. Human capital is also a regarded as key factor in generating higher productivity and economic . Education institutionalizes information and knowledge accumulated previously, i.e. turns it into an instrument of sustainable removal of uncertainty, as well as an instrument of national or international influence on the intelligence of people. Education is an institutional filter: if the information transformed into knowledge, and knowledge into rules, patterns and norms, then information entered in the social organism, that is, it passed the process of knowledge institutionalization, which is possible due to the implementation of educational activities. Recent trends whereby the economies of developing countries have been growing significantly faster that the developed ones is likely to continue in the future. Relative inequality in per capita incomes would be reduced considerably by 2050 . However, absolute differences would remain pronounced and could even increase further, given the current huge gaps in absolute per capita incomes. Moreover, inter-country and inter-regional inequalities within the present-day developing world would tend to become more pronounced.

Economic theory defines the Institute of Education as one of the most important socioeconomic and law institutions, functioning in order to meet the demand of society for educational product and flexible in responding to all the social changes and processes. Institute of Education today ceases to act as a center of social and cultural values transmission, and becomes a producer of high-value products, as a set of educational goods and educational services. This product is formed as a result of treatment with the help of educational tools and is estimated on the labor market by a potential employer.

The key role of education requires a special relationship to him by society and the state, determines the dynamics of socio-economic development, acts simultaneously on two interrelated and interdependent markets - market of educational products and services and the labor market. Education - this is one of the most dynamic and investment attractive areas of the market economy. According to expert estimates, in the developed countries, the rate of annual increase in the volume of demand and supply of educational services is $10-15 \%$ (Litvinova et al., 1997). 
Educational product is a result of the production process in the educational activity, in which knowledge is a kind of commodities, represented as a set of specific professional data. The result of the operation of the education institution embodied in the form of a commodity is a diploma of the particular specialty, which serves as a commodity purchased by the consumer.

Gaining knowledge by the society is realized through educational activities, as a result of which an institution provides educational product to the consumer. Considering the results of educational activity, that is, the knowledge obtained by the consumer and embodied in the form of commodity as a state diploma of certain speciality, one should pay attention to the specific characteristics of education as a commodity, i.e. a public good. Education as a public good is a result of a long historical social evolution of a society. Consolidating the results of science, education develops cognitive and practical properties of a social person, enabling them to meet continuously rising social needs. It helps the action of complex mechanisms in individual and social human activity, reproduces integration and differentiation of diverse social ties. According to the current scientific understanding educational product is an economic product, which is interpreted as the result of economic activity and is presented in the material form as fulfilled works and provided services that could be provided to the consumer during his life time.

On one hand, education is a personal, individual property, the main profit of which has economic properties, because consequently it is embodied to the income level of its owner. The institute of education is aimed at equipping the consumer of educational services with knowledge and competencies that will open access to obtaining the certain social position and material income. People treat knowledge as something that belongs to them, for the benefits of education that used in work and social activities. In this sense, the attitude of every person to education as to the general condition of their vital activity is a part of the common property. However, because of the complexity of the research object and the needs for a multidisciplinary approach, this issue is still in the development stage. On the other, education is an institution of socialization, coordination and practical integration of generations, providing professionalized transformation of socially significant information into knowledge, which convey generalization and potential smoothing sharp edges of the national inconsistencies arising from traditional norms and rules that make up the national characteristics of the cultural heritage.

The economic nature of education has been recognized by the classics of economics in the framework of the value labor theory. Many questions are described: the productive and efficiency education nature as a human capital investment in its future (Adam Smith); the analysis of the education costs as part of the of the labor power reproduction cost (D. Ricardo); the wages dependence on the education spending level (K. Marx); the education investments that considered to increase not only the human capital growth of its own productivity, but also for other workers (A. Marshall); the correlation of education investments in the economy and the GDP growth rate(J.M. Keynes); human capital as an external production factor, that is raising the economy productivity and efficiency (R. Solow) (Mukimbekov, 2011).

William Petty, the first focused on the high importance of citizens' wealth of knowledge as an element of the wealth of the kingdom (Petty, 1940; Petty et al., 2000). Adam Smith compared the person with a pre-acquired specific knowledge and skills, with high-tech expensive machine: "... The work done by the machine until the occurrence of wear and tear, return on investment in its capital, bringing a profit of at least normal levels. Man, get an education; it can be compared to an expensive machine discussed above. It is believed that the work that he has learned to perform, to be paid above the wages of ordinary employees, and allow him to recover all the costs of education, bringing a profit, which, at least, brings generally equal assets, but it must be done in a reasonable time" (Smith, 1962; Kobersy et al., 2015).

The concept of "human capital" was formed into a single concept in the late 1960s. Schultz, Becker, Denison, George. Kendrick, Robert Lucas - the founders of the concept of human capital considered education not only by the consumption of certain forms of 
educational services, but also on the part of productive capital investments (Toffler, 1980). So, Mr. Becker was first used method for evaluating investment in physical capital for comparing the efficiency of investment in human capital, using which he analyzed, changes in the distribution of income after increasing the level of human capital among the masses as well as the effect of the reproduction process on the welfare of individual countries (Becker, 1993).

In recent years, a number of studies of correlation between level of education and GDP growth has been conducted (Hanushek, Vosmann, 2012). It identified the importance and value of education for the promotion of research and development, as well as for the dissemination of technologies (Vegelers, 2010). It was found that the higher percentage of educated people in the country's population, the higher the rate of economic growth (Maddison,2006). The rate of human capital formation or investment in education was identified early on as a key influence on rates of economic growth (Barro, 1991) and growth theorists now place great emphasis on this variable as a determinant of the wealth of nations. Lucas (1988) developed an endogenous (within the economy) growth model that considers human capital as one factor of production and schooling as a means of human capital accumulation (Harmon, 2006).

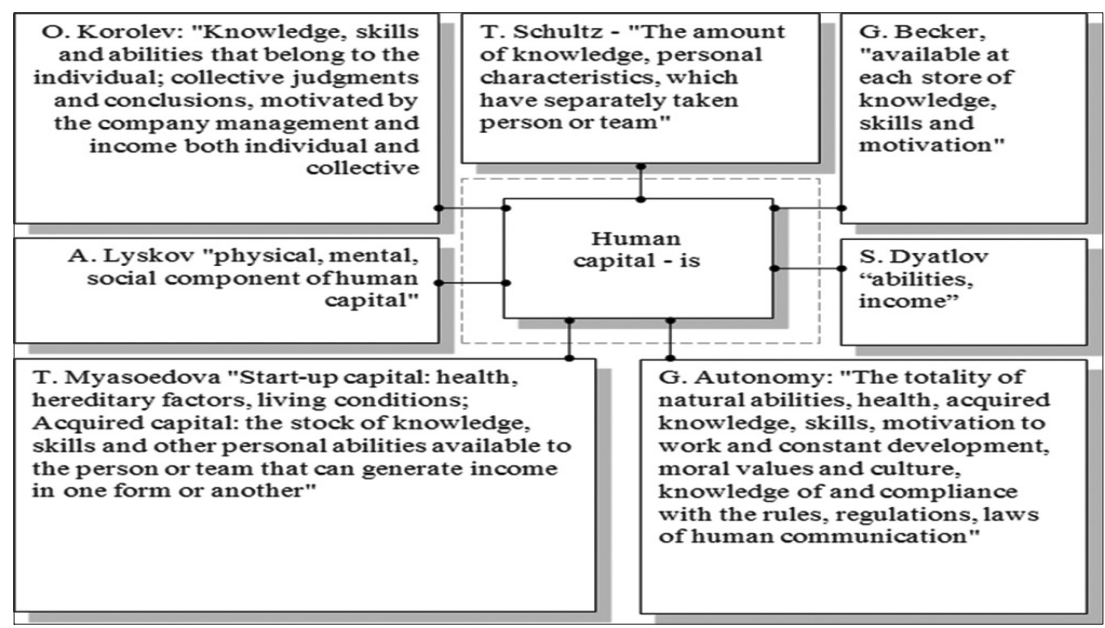

Figure 1 - Classification category of "human capital"

Today special importance is given to the problems of the transformation of the education institution in the period of globalization, unification and standardization, as well as between technology and the information revolution, which generate the need for the new educational forms that can flexibly respond to changing demands for knowledge and professional skills. This problem is reflected in the works of V. Andruschenko, V. Bochkova, K Wazzin, T. Voronininoy, M. Galushkina, V.Gurova, A. Davydov, A. Yegorovna, O. Ereminoy, V. Zhuravsky, C Zahariya, I. Kalenyuk. A., S. Krihels, V. Kutsenko, V. Logacheva, S. Mihats, E.Morgunova, S. Nikolaenko, E. Pakhomov, A. Petrov, N. Pruel, V. Tambovtseva, E. Hershberg.

Scientific methods of systematic and comprehensive approach are served as methodology of the study: historical and logical method is allows to reveal the nature of the historical educational forms and its relationship with the economic system; dialectical method, on the basis of which has been verified by contradictory nature of the functions and status of educational activities and its role in the development of economic systems; induction and deduction methods which made possible to generalize and systematize the modern trends of development of institutional reforms of educational activities; method of analysis and synthesis that are characterized by patterns of institutional development of educational activities to enable it to organically be involved in the process of globalization and socialization of economics; method of institutional approach, which has allowed to present an educational segment of the economic system as a set of rules, regulations, 
traditions and special organizations (educational institutions), which provide the process of education transmission of socially significant information.

One of the main tasks of legislation in the sphere of education is to ensure and protect citizens' constitutional right to education, and to create legal guarantees for the free functioning and development of both the educational system as a whole and all its components. Inadequate provision of the above guarantees by states is a hindrance in the realization of the planned reforms. Academic literature contains very different, sometimes even mutually exclusive interpretations of the concept of "lifelong education", from the emergence of a new, global educational system to the principle of continuity that becomes decisive for the functioning of any educational system during the epoch of globalization. The opportunity to get a free professional education only once in one's lifetime, and the duty to "work out one's diploma" for several years, were not conducive to people's self-improvement and permanent creative growth. Furthermore, the basic knowledge one received was virtually sufficient for a lifetime. The opportunities for lifelong education that were created by those circumstances allegedly gave a powerful impetus to the development of lifelong education. (Astakhova, 2010)

From the economic point of view knowledge is a commodity in the relations of commodity-monetary exchange and are traded in the market of educational services, education can also be seen as an institution of social and economic exchange. Education offers the market a product that, as well as any product of exchange, has a use value and exchange value, i.e. the ability to meet the needs of the consumer, which is reflected in consumer utility from consumption of educational services and the ability to exchange into the money that is paid by the consumer of an educational product. An educational product may be represented in the form of commodities as knowledge, which is set of information of a specific vocational orientation, collected into educational programs within a particular specialty. The result of this commodity form embodiment is a diploma which, being bought and sold in the market of educational services, serves as goods in commodity-money exchange, both at the education market and the labor market.

The model of market relations in the higher education system is presented regarding the relationship between higher education institutions engaged in training and retraining of young professionals, between enterprises, which are consumers of young professionals, and young professionals themselves as specific goods, produced as a result of educational services. However, due to the same reason, parents, school, environment, and surrounding people, as well as the graduate himself could be called the manufacturer of this particular product. This is confirmed by the fact that in the formation of professionally significant knowledge and skills that are used by employers in the labor market, not only the university is involved, but also the family, environment. An important aspect here is the self-education in the period of study at the university, parallel training in various courses, getting extra specialties. In addition, professional qualities cannot be viewed in isolation from other personality characteristics that are significant during both employment, and occupation.

Another important aspect of education identification is considered from the point of view of the public, private or mixed benefit. Consideration of education from the perspective of a public good allows one to emphasize its fundamental property - non-competition, the essence of which is that every person originally acts as a co-owner of the knowledge belonging to the whole society. Consumption of education benefits by an individual should not be excluded from consumption of the results of their operation for other people, which characterizes the non-competition of education. Consumption of knowledge by certain people does not lead to a reduction in consumption of the same knowledge by others, since knowledge are inseparable (Pruel N,2001)

When considering education as a public good and analyzing its external effect, the presence of high levels of uncertainty should be noted, which creates insurmountable difficulties of quantitative changes in the public benefit and creates the possibility of opportunistic behavior of the subjects of educational process. In addition, there are circumstances indicating irrational economic behavior of economic agents and the 
occurrence of information asymmetry, i.e. the uneven distribution of information between the state and citizens.

The main task of the education market is to balance the supply and demand of these services and meet their needs. Demand for educational product is determined by many social and psychological factors, starting with adherence to family traditions. From the point of view of economic motives, the most important is the salary that the consumer of educational services is able to receive after graduating from higher educational institution, and the prospect of return on investment in education. One can make the following assumptions about the demand for education:

- consumer demand, based on current consumption is less than the demand of those who are oriented toward future income (ceteris paribus);

- demand for contract training will decrease with an increase in the cost of education (ceteris paribus);

- demand will increase with an increase in the differences in earnings of persons with higher and secondary education in favor of the former;

- the demand for educational services to a particular profile is derived from the demand for specialists in this profile and the level of their income;

- with increase in the age of educational services' consumers, the alternative expenses rise as well, which makes the demand for educational services more flexible.

In the context of economic transformation the "non-functional demand" remains high enough and touches upon universities and specialties displaying a prestigious position in society, the so-called "Veblen Effect", which in opposition to the law of demand unreasonably puts up the prices for prestigious specialties. This applies to the world's most prestigious universities of Harvard and Stanford, as well as Russian (Moscow State University, MGIMO).

With regard to the analysis of the supply of education services, it should be remembered that the Institute of Education "forges personnel" and should therefore be focused on the needs of society in general and employers in particular. However, some difficulties and peculiarities should be pointed out. An educational institution operates simultaneously in two markets: the education market and the labor market. The university provides educational services of a certain type to the society and at the same time presents the results of its activities to the labor market, consumers of which are businesses and organizations in different fields of economy. This dual nature of the university activity is making considerable confusion in the definition of its products, target markets and consumer groups.

The supply of educational services within a single educational space is carried out by state and private universities, which occupy one third of the market and increase competition. Given the market structure the market of educational services is a market of monopolistic competition. This is implied by: firstly, educational product differentiation both as to its consumer characteristics and in terms of the quality. It is referred to education in different fields, faculties, universities and levels of teaching. Secondly, the high sensitivity to economic conditions, a significant factor of seasonality, a significant influence of advertising, fashion, awareness, education institute dependence of political and economic institutions. Thirdly, distinct segmentation of demand for services based on income, prices, users' subjective evaluation of the supplier's ability to provide certain services, the importance of a service, lifestyle. Fourthly, the general capacity of the market and the absolute benefits of existing enterprises in the industry on the costs of providing services and benefits to consumers, the positive effects of scale(Astakhova,2013)

In assessing the expected benefits of investment in human capital for individuals, researchers isolated and short-term factors affecting the change in the dynamics of demand of people with consumption of educational services.

The long-term factors include:

1. A high level of wages for a future life;

2. A greater satisfaction from the work chosen for life (moral benefits); 
3. The achievement of higher social status. It is assumed that in a modern society can rise from the bottom to the top, and it requires only the effort. There is a so-called "lifts" social mobility, one of which is education;

4. The affects the orientation of their children (the continuity of generations, the continuation of the profession of parents). For parents, the child's higher education serves as proof of the viability of the family, the consistency of its material and social resources;

It should be noted that the educational space within the market is non-uniform both in terms of students, educational institutions, and from the point of view of the proposed product. In one state, you can find a lot of educational institutions that due to a number of factors have different quantitative characteristics of educational space. These factors include the profile of the university, teaching personnel and different entry requirements. One of the main factors that determine the boundaries of the market is the price factor. However, today non-price factors are becoming more and more important in the competitive relationship in the market of educational services.

This means that educational institutions are trying to attract the consumer using nonprice methods, focusing on the range of additional related services, so-called complement services. The latter include: the organization of extracurricular activities, broadening the range of educational services through the provision of training on an additional speciality, organization of scientific activity of students, as well as scientific conferences and seminars.

The implementation of lifelong multilevel education must lead to the creation of educational institutions with a multilevel organization of students training. Training in such institutions must be implemented according to integrated curricula and educational programs of various educational levels: primary, secondary, higher and supplementary ones. The upbringing component of the integrated training and upbringing process being implemented in the above structures must be an important component of their activity. Such activities may result in a network of educational institutions providing opportunities for a changeover to multi-level, multi-tier, successive and variable educational problems. Therefore, in spite of the fact that the overwhelming majority of educational institutions implement the idea of lifelong education in practice by organizing joint activities or creating associations of legal entities interconnected by an agreement or shared goals of the above concept, in our opinion, the concept of lifelong education can be implemented to the best extent in educational institutions (complexes) comprising all the basic educational activity structures, from preschool to postgraduate education, moreover, within the framework of a single legal entity.

One of the most powerful factors of non-price competition between universities is teaching personnel. Its qualitative characteristics can be divided into formal and informal. The former should include the number of academic degrees and titles per one school, to informal - the credibility of teaching staff, the nature and level of interpersonal relationships, the efficiency of their interaction, the ability to empathize. A significant role among the nonprice factors is played by an opportunity to provide further employment of students, which opens the way for students to reduce the transaction costs of future job search with the necessary level of pay and prestige. The characteristic features of the educational market, like any other, are the uncertainty and risks, which include: "supply and demand shocks": changes in economic and political stability, a sharp change in prices for resources, in tax policy, as well as natural disasters.

Demand for the products of companies operating in a monopolistic competition is not perfectly elastic, but its elasticity is high. For example, the adherents of Western European education are willing to pay for it more than for domestic education -, but if the price difference is too large, then the buyer will always find in the market analogues of less wellknown companies at a lower price. Therefore, the institutions that produce intellectual human capital should have a balanced approach to the positioning of their own advantages.

Currently, the process of modernization and reform of education in virtually every country in the world. And, despite the differences in systems and approaches in this field, global trends in education have much in common, in particular: 
- Changes in the objectives and functions, strengthens its innovative componentprevails over the cultural characteristics of the developing countries;

- Improves the quality of education in line with the changing needs of society involves real implementation of new educational technologies, changing the whole system of training and retraining of highly qualified specialists;

- Focus on the principles of lifelong education is the introduction, asthe neweducational technologies, and finding new ways of presenting educational services tailored to the needs of school-leavers and students;

- Formation of new goals of the school, which in the twenty-first century. It becomes a social institution to meet the needs of society in vocational education (Dobrynin et al., 1993).

Activity of universities is carried out today in an increasingly competitive environment. This policy defines the institution of higher schools, which tend to attract students and raise their ranking to become competitive in the provision of qualitative educational services. Global trends in the development of education, the situation developing in the Ukrainian system of higher education urgently require a deep and comprehensive renovation of the structure and content of higher education, consistent and prompt implementation of innovative technologies of training and education, modernization of the state educational policy, reviewing not only the legal basis for the functioning of higher education but also rethinking of the mission of the higher school, its strategic objectives.

There are several strategies to improve competitiveness: the horizontal and vertical integration processes. Horizontal - the entrepreneurial activities of the university, the expansion of educational services, internationalization of education and integration into the international educational space and integration processes "university-science-business." Vertical - introduction of the concept of lifelong education, "school-university-business."

During the fierce competition, which higher education institutions have been forced to face within the market space, there is a selection of educational institutions. In addition to competition, to overcome which universities have to spend a certain part of their potential, higher education institutions need to look for and to optimize self-financing sources, both public and private. The ones to survive are those who meet the needs of the market today, try to minimize costs, as well as those who can anticipate changing trends in demand for educational services and take into account its forecast. They have to, in the face of fierce competition in a timely manner extend and change the range of services and products that make up the educational product, offering the market new educational forms, using new methods and training programs, advanced scientific and technical achievements with the logistics of the educational process.

\section{REFERENCES}

1. Marginson S. Globalisation and higher education // 2007. Ed. Working Papers, №8.

2. Astakhov V.V. Instrumental and technological directions to ensure economic security of enterprise // International Review of Management and Marketing. 2016. 1(6). pp. 172178.

3. Pruel N. Education as a public good: the reproduction, distribution and consumption // SPb., 2001. $187 \mathrm{p}$.

4. Vegelers R. Contribution of universities to economic development // 2010. Economics of Education. №2. pp. 74-80.

5. Shestopal S. Education as Market Product: Identification Problems // Mediterranean Journal of Social Sciences, 2015. №5. pp. 211-216.

6. Mukimbekov M. Economic nature of the education market, and some areas of the modernization of higher education // 2011. Economics of Education. №5. pp. 4-15.

7. Rivkin, S. "Teachers, Schools, and Academic Achievement" // Econometrica, 2005: 417458.

8. Harmon C. Economic and social impact of higher education. Geary institute. 2006.

9. Astakhova K.V. et al. The role of education in economic and social development of the country//International Review of Management and Marketing. 2016. 1(6), pp. 53-58. 